\title{
Virology, Clinical Features and Diagnosis of COVID 19: Review Analysis

\author{
Bhusal L, ${ }^{1}$ Amgain K, ${ }^{2}$ Dangal G, ${ }^{3}$ Tamang PD, ${ }^{4}$ Shahi P, ${ }^{5}$ Budhathoki P, ${ }^{6}$ Paudel AK ${ }^{7}$
}

${ }^{1}$ Department of Emergency and General Practise Shree Birendra Hospital, Kathmandu, Nepal.

${ }^{2}$ Department of Clinical Anatomy and Cell Biology, Karnali Academy of Health Sciences, Jumla, Nepal.

${ }^{3}$ Department of Obstetric and Gynecology,

Kathmandu Model Hospital.

${ }^{4}$ University of Huddersfield, UK.

${ }^{5}$ Research and Development, Manavta, Nepal.

${ }^{6} \mathrm{Dr}$ Iwamura Memorial Hospital, Bhaktapur, Nepal.

${ }^{7}$ Metro City hospital, Pokhara, Nepal.

\section{Corresponding Author}

Kapil Amgain

Department of Clinical Anatomy and Cell Biology,

Karnali Academy of Health Sciences, Jumla, Nepal.

E-mail: dr.kapilamgain@gmail.com

\section{Citation}

Bhusal L, Amgain K, Dangal G, Tamang PD, Shahi $P$, Budhathoki P, Paudel AK. Virology, Clinical features and Diagnosis of COVID 19: Review analysis. Kathmandu Univ Med J. 2020;COVID-19 Special Issue 70(2):75-9.

\begin{abstract}
COVID-19 requires unprecedented mobilization of the health systems to prevent the rapid spread of this unique virus, which spreads via respiratory droplet and causes respiratory disease. There is an urgent need for an accurate and rapid test method to quickly identify many infected patients and asymptomatic carriers to prevent virus transmission and assure timely treatment of the patients.
\end{abstract}

This article aims as an outcome of review of the evidence on viral load and its virulence of SARS-CoV2, so that it will help in further understanding the fact useful for investigating and managing the COVID-19 cases.

A search of available evidence was conducted in pub-med "COVID-19 viral load and virulence" and its associated characters world-wide and Google Scholar to capture the most recently published articles. The WHO and Centre for Disease Control and Prevention (CDC) database of publications on novel coronavirus were also screened for relevant publications. Abstracts of 55 articles were screened by two authors and 15 were included in this study based on the inclusion criteria.

SARS-coV2, the causative agent of COVID-19 falls under the coronavirus family but it has higher infectivity compared to SARS and MERS with higher reproduction numbers(Ro). Virulence has been found to be different throughout the world, however lower compared to SARS and MERS,till date. The most common clinical features have been found to be cough and fever. RT - PCR remains the most sensitive and specific method for the diagnosis of COVID-19 although it is time consuming, costly and requires highly skilled human resources. Hence, newer modalities like RT- LAMP can be alternative for point of care diagnosis as this is both cost effective and requires less skilled human resources.

Despite recent advances in disease diagnosis and treatment outcomes using latest technological advances in molecular biology, the global pandemic COVID-19 remains a major headache for governments across the world due to limited testing capacity and lack of appropriate treatment and vaccine.

\section{KEY WORDS}

Coronavirus, COVID-19, Diagnosis of COVID-19, Serological tests, Virulence

\section{INTRODUCTION}

The novel coronavirus disease 2019 (COVID-19) caused by severe acute respiratory syndrome coronavirus 2 (SARS-CoV-2) began in Wuhan, China, in December 2019. The current COVID-19 pandemic continues to spread and impact countries across the globe. ${ }^{1}$ On 12 January 2020, the World Health Organization (WHO) temporarily named the new virus as 2019 novel coronavirus (2019 nCoV). ${ }^{2}$ WHO officially declared COVID-19 as a pandemic on $11^{\text {th }}$ March 2020 which is three months from the possible start of the outbreak. As of $12^{\text {th }}$ August 2020, 20,521,644 confirmed cases and 745,918 deaths has been reported in 215 countries since $31^{\text {st }}$ Dec $2019 .^{2}$ The experience from countries with higher number of cases such as China, Italy and Spain show that COVID-19 requires unprecedented mobilization of health systems. ${ }^{3}$

2019 nCoV is a unique virus that causes respiratory disease, which spreads via respiratory droplet and contact. In a phylogenetic analysis of 103 strains of SARS-CoV-2 from 
China, two different types of SARS-CoV-2 were identified, designates type $\mathrm{L}$ and type $\mathrm{S} .{ }^{4}$ It spreads via both direct and indirect transmission, directly by contacting through the aerosols and indirectly by touching the contaminated surfaes in the immediate environment exposed with positive cases. ${ }^{5}$ It seems that SARS-CoV-2 can be transmitted throughout the course of illness. Viral RNA levels from upper respiratory specimens appear to be higher soon after symptoms onset compared with later in the illness. ${ }^{6}$ It is uncertain how long a person remains infectious. There seems to be wide variation in duration of viral shedding based on disease severity. ${ }^{7}$ The median duration of viral RNA shedding from nasopharyngeal or oropharyngeal specimens was 24 days and longest was found to be 42 days. ${ }^{8}$ So, the risk of transmission from an individual with SARS-CoV-2 infection varies by the type and duration of exposure, use of prevention measures and likely individual factors. Most secondary infections have been described among household contacts, in congregate or health care setting when personal protective equipment (PPE) was not used and long-term care facilities and in closed setting as the virus can be present in the exposed environment. This review article aims to review evidences on viral load and its virulence so that it will help in understanding about the fact on managing and investigating cases.

\section{METHODS}

A review search of available evidence was conducted in PubMed, PMC and in COVID-19 on viral load and virulence and its associated character world-wide with the search keywords; coronavirus, virulence, infectivity, clinical features and diagnostics, serological tests, severe acute respiratory syndrome coronavirus 2 (SARS-CoV-2), 2019nCoV, SARS-CoV, MERSCOV and COVID-19 in combination with treatment and pharmacology. A gray literature search was also performed using the same keywords on Google Scholar to capture the most recently published articles.

The studies regarding virology, virulence, pathogenesis, infectivity, clinical feature and diagnostics about COVID-19 or SARS-COV-2 were included. We included interim guidance from WHO on laboratory testing for COVID-19 that was published on 19 of March, 2020 along with guidelines about COVID-19 on laboratory testing present in the CDC website. ${ }^{9}$ The article in English language and full text available were included in this review. Articles focused on other viral pandemics with no mentioning or discussion of COVID-19 were excluded. Non-English literature and non-full text articles were also excluded.

\section{RESULTS}

Clinical diagnosis of COVID-19 becomes problematic due to similar manifestations, especially during seasonal flu, that is why confirmation of COVID-19 depends on the detection of SARS-CoV-2 nucleic acid by reverse-transcriptase polymerase chain reaction (RT-PCR). ${ }^{10}$ Laboratory confirmation of the suspected cases are important for appropriate management of the cases including isolation from others. Although the virus (severe acute respiratory syndrome coronavirus (SARS-CoV-2) nucleic acid real time polymerase chain reaction (PCR) test has become the standard method for diagnosis of SARS-CoV-2 infection, these real-time PCR test kits have many limitations such as exacerbating variability in the amount of viral RNA and increasing the chances of skewed RT-PCR results. In addition, high false-negative rates were reported. ${ }^{11}$ Recent advances in Nucleic Acid Testing include RT-LAMP (Reverse Transcriptase Loop Mediated Isothermal Application) which is a time saving and cost-effective reliable test with potential of use for point of care services. ${ }^{11}$ The RDT has become the current helpful diagnostic method for the diagnosis of COVID-19 in mass screening and going for PCR test afterward if it comes positive.

COVID-19 falls under the coronavirus family but it has higher infectivity compared to SARS and MERS with higher reproduction numbers. Virulence has been found to be different throughout the world. The lowest virulence has been seen in China where CFR is $0.7 \%$ while Italy has the highest CFR of $7.2 \%$. Virulence is lower compared to SARS and MERS. The most common clinical features have been found to be cough and fever. Less common symptoms like stroke, dermatological rash and Kawasaki syndrome like disease have also been shown in children. RT - PCR remains the standard method for diagnosis of COVID 19 although it is time consuming, costly and requires highly skilled manpower. Serological tests based on detection of antibodies and antigens aim to primarily determine the extent of outbreak in the community and give ideas about exposure to viruses. It cannot be used for diagnosis of acute infection. Nucleic acid amplification tests along with CT scans have been used in multiple countries for better diagnosis and higher sensitivity when both are done together. ${ }^{12}$

\section{Viral Structure}

Coronavirus belongs to the family coronaviridae and subfamily coronavirinae of order nidovirales. Its subfamily includes four genera: alpha, Beta, Gamma and Delta coronavirus. ${ }^{13}$ The new Cov, 2019 belongs to the beta coronavirus based on sequence analysis. ${ }^{13}$ It is a single stranded RNA-enveloped virus. The single strain of new Cov19 is $29.9 \mathrm{~kb}$ while SARS-CoV and MERS-CoV have positivesense RNA genomes of $27.9 \mathrm{~Kb}$ and $30.1 \mathrm{~Kb}$, respectively. The two third of the viral RNA translates two polyprotein pp1a and pp1ab, and encodes 16 non-structural proteins (NSP), while the remaining ORFs encode accessory and structural proteins. The rest part of the virus encodes four essential proteins which are spike(S) glycoprotein, envelop (E) protein, Matrix (M) protein and nucleocapsid (N) protein, and several other accessory proteins to help virus 
break the host immunity. ${ }^{14}$ The Structural Spike protein(S) protein binds to the angiotensin converting enzyme 2 (ACE2) receptor after binding to this protein it uses host cell receptor and endosomes to enter cells. ${ }^{14}$ After entering the cell, the virus synthesizes RNA from RNA dependent RNA polymerase. Then after the structural proteins are synthesized which then assemble and then release the complete viral particles. ${ }^{14}$

\section{Infectivity}

Infectivity is the proportion of persons exposed to an infectious agent who become infected by it. To understand infectivity in epidemiology, it is the ability of a pathogen to establish an infection. ${ }^{15}$ COVID-19 infectivity or degree of transmissibility has raised much more challenges to health care providers. Mathematical formula with clear and acceptable assumptions is used to calculate the infectivity index in general. The "basic reproduction number" termed $\mathrm{RO}$ is used which indicates the expected number of cases directly infected by one contagious case in a population that everyone is supposed to be susceptible. RO is affected by the properties of susceptible people at the start and the density of the population, the infectiousness of the organism and the rate of disappearance of cases by recovery or death. The infectivity of the virus has been observed with Ro between 1.95 to 6.47 . This variation in the index were because of the calculation done in different time of the disease epidemic in different countries. ${ }^{16,17}$

\section{Virulence}

Virulence is defined by the ability of a microorganism to cause disease in the host. ${ }^{18}$ The virulence of a disease is usually measured on the basis of indicators such as mortality rate and disability. The spectrum of disease ranges from mild to severe; and most of the infections are mild. ${ }^{18}$ Compared with the previous two epidemics (SARS and MERS), the case fatality rate was lower with $2 \%$ and only $15 \%$ of patient would seek hospital treatment in Covid-19. However, the case fatality rate of SARS and MERS was $10 \%$ and $34 \%$ respectively. ${ }^{19-22}$ In a report from Chinese center for disease control and prevention that included approximately 44,500 confirmed cases $81 \%$ cases had Mild disease (No or Mild pneumonia), 14\% cases had severe disease (SOB, Hypoxia and involving more than 50 pct. of lungs on imaging), $5 \%$ had critical disease (with respiratory failure, shock or multi organ failure) and overall Case fatality rate (CFR) was $2.3 \%$ with the deaths seen only among critical patients. But the case fatality rate in other parts of china is different e.g. In Beijing the CFR was $0.9 \% .{ }^{21}$ The case fatality rate in china ranges from $5.8 \%$ in Wuhan to $0.7 \%$ in rest of the china. ${ }^{20}$ Patients with advanced age and underlying comorbidities were found to have more fatality rates. ${ }^{21}$ However, there is higher number of deaths in recent pandemic due to rapid spread of the disease e.g. In Italy there was case fatality of $7.2 \%$ till mid-March. ${ }^{22}$
Case fatality rates vary significantly ranging from $18.94 \%$ in France, Italy $14.44 \%$, United Kingdom $14.3 \%$, Spain 9.4\%, USA 5.58\% Cuba 3.76\%, India 2.79\%, South Korea $2.31 \%$ and Nepal having $0.37 \%{ }^{22}$

\section{Clinical features}

COVID-19 manifests with a wide clinical spectrum ranging from symptomatic patients to multi organ dysfunction and septic shock. ${ }^{23}$ Pneumonia appears to be the most frequent manifestations of infection, characterized primarily by fever, cough, dyspnea. In a study done by Nascimento et al. fever was present in $82 \%$ with cough in $61 \%$, muscle aches in $36 \%$ and dyspnea in $26 \% .{ }^{23}$ Although not noted in the majority of the patients, gastrointestinal symptoms like nausea and diarrhea may be the presenting complaint in some patients. ${ }^{23}$

Ocular manifestation like conjunctivitis have also been seen. ${ }^{24}$ In children, reddish purple nodules were seen as chilblain like lesions varied from vesicles, pustule, maculopapular eruptions to livedo or necrosis. ${ }^{25}$ COVID-19 presenting with large vessel stroke have also been reported. Kawasaki disease like features have also been seen in children with COVID-19. ${ }^{26}$ Anosmia has also been reported in conjunction with well reported symptoms of corona virus. ${ }^{27}$ Recently new manifestation of COVID-19 with venous and arterial thromboembolic disease have been found due to excessive inflammation, hypoxia, immobilization and diffuse intravascular coagulation (DIC). ${ }^{28}$ Several complications of COVID-19 have been found with respiratory failure, cardiovascular complications with arrhythmias and inflammatory complication like guillainbarre syndrome. ${ }^{29}$

\section{Diagnosis}

WHO has recommended different testing like Nucleic acid amplification tests (NAAT), Serological testing, Viral Sequencing and Viral Culture. ${ }^{30}$ The virus has been detected in completely asymptomatic individuals, e.g. in a recent study from Italy, showing that $44 \%$ of the laboratoryconfirmed cases lacked symptoms. ${ }^{31}$

\section{A. Nucleic Acid Amplification Test}

NAAT for COVID-19 virus is one of the important tests used worldwide. Routine confirmation of cases of COVID-19 is based on detection of unique sequences of virus RNA by NAAT such as real-time reverse-transcription polymerase chain reaction ( $r$ RT-PCR) with confirmation by nucleic acid sequencing when necessary. A biosafety cabinet in a BSL-2 or equivalent facility is necessary for RNA extraction. The target gene to be amplified by RT-PCR can be the RdRP gene (RNA dependent RNA polymerase gene) or E gene (Envelope protein) or $\mathrm{N}$ gene (Nucleocapsid Protein). ${ }^{32}$ Different countries use different target genes. The analytical sensitivity for detection is higher with RdRP and $E$ gene compared to $\mathrm{N}$ gene..$^{32} \mathrm{WHO}$ recommends RdRP and $\mathrm{E}$ 
gene for detection while CDC uses $\mathrm{N}$ gene for detection. ${ }^{32,33}$ In our country Nepal, RT-PCR has been done by NPHL and it is based on target gene recommended by WHO. ${ }^{34}$ There are numerous challenges with rRT-PCR like:

a) It is difficult to do this testing in smaller peripheral hospitals with lack of proper equipment and skilled manpower

b) It doesn't identify people who recovered from infection and are in early stage of their infection

c) Lack of enough test kits and reagents

d) Improper sample collection, handling and transport may result in false negative.

False positive and false negative results have been reported in RT-PCR test. ${ }^{10,35}$

\section{B) Serological testing}

Serological tests are blood-based tests that can be used to identify whether a person has been exposed to a particular pathogen or not. There are several modalities of testing like ELISA, CLIA, Lateral flow assays (LFA). ${ }^{36}$ Enzyme-linked immunosorbent assays(ELISA) are more rapid serology tests performed in a lab that provide a readout of antigen antibody interaction. ${ }^{37}$ Chemiluminescent immunoassay (CLIA) shows whether a patient has antibodies to a pathogen by displaying a fluorescent signal when patient antibodies interact with virus proteins. ${ }^{37}$ Lateral flow assays (LFAs), also called rapid diagnostic tests (RDTs) display a colorimetric, qualitative readout of the presence of antibodies. These are often used in point-of-care settings. The patient sample is flowed over a membrane that has the target antigen anchored. If the sample contains antibodies specific to that antigen, they form a complex that results in a colored band on the strip. ${ }^{38}$ COVID-19 antigen detection RDTs and COVID-19 antibody detection RDTs are different. There are two types of COVID-19 rapid tests currently in use or in development: direct SARS-CoV-2 antigen detection and indirect antibody detection tests. ${ }^{40}$ According to WHO, Serological testing can be used for assessment of current outbreak and and determination of attack rate and extent of outbreak retrospectively. ${ }^{32}$ Unlike rRT PCR, these antibody tests have a larger window for finding COVID-19. One or more negative results do not rule out the possibility of COVID-19 virus infection. Limitation of this test is that there has been cross reactivity with other members of corona family. ${ }^{38}$
Rapid tests are qualitative or semi-quantitative in vitro diagnostics (IVDs), used singly or in a small series, which involve non-automated procedures and have been designed to give a fast result. COVID-19 antigen detection RDTs diagnose the presence of a protein of the virus in body fluids - mostly in secretions of the upper respiratory tract. For COVID-19, rapid tests may take around 10-30 minutes until giving a result compared with about four hours for molecular tests done in large series, or more if samples must be transported to a distant testing laboratory COVID-19 antibody detection RDTs diagnose antibodies produced by white blood cells of the infected person during the infection. They are mostly detected in the blood. But it takes a few and up to 4 days for IgM test to be positive and and 14 days for IgG to be positive. ${ }^{39}$ COVID-19 antibody detection immunoassays (serology tests) (ELISA, IFA and RDTs) are not recommended by WHO for identification of COVID-19 infections. ${ }^{32}$ They detect recent or previous exposure to COVID-19. Dynamics and specificity of the different Ig classes (IgM, IgG and IgA) are still under investigation and false positive reactions may occur. Rapid antibody testing has been used by the Nepal government for contact tracing.

\section{CONCLUSION}

COVID-19 requires unprecedented mobilization on health systems to prevent the rapid rise of this unique virus that causes respiratory disease, which spreads via oral and nasal droplets. COVID-19 falls under the coronavirus family but it has higher infectivity compared to SARS and MERS with higher reproduction numbers. Virulence has been found to be different throughout the world which is lower compared to SARS and MERS. The most common clinical features have been found to be cough and fever. There is an urgent need for an accurate and rapid test method to quickly identify many infected patients and asymptomatic carriers to prevent virus transmission and assure timely treatment of patients. RT - PCR remains the one of the best methods for diagnosis of COVID-19 although it is time consuming, costly and requires highly skilled human resources. Hence, newer modalities like RT- LAMP can be alternative for point of care diagnosis as this is both cost effective and requires less skilled human resources. Despite recent advances and increasing studies, the global pandemic COVID-19 remains a major headache for governments across the world due to limited testing capacity and lack of appropriate treatment and vaccine. 


\section{REFERENCES}

1. W Zhu N, Zhang D, Wang W. China Novel Coronavirus Investigating and Research Team. A novel coronavirus from patients with pneumonia in China, 2019. New England Journal of Medicine. 2020;382(8):727-733. doi:10.1056/NEJMoa2001017

2. WHO | Novel Coronavirus - China. WHO. Published online 2020.

3. WHO Coronavirus Disease (COVID-19) Dashboard. Accessed May 8, 2020. https://covid19.who.int/

4. On the origin and continuing evolution of SARS-CoV-2. Accessed May 8, 2020. https://www.ncbi.nlm.nih.gov/pmc/articles/PMC7107875/

5. Khadka S, Saeed H, Bajgain Y, Shahi J, Yadav TP, Gupta RP. Different Modes of Transmission and Containment Strategies for COVID-19. Europasian Journal of Medical Sciences. 2020; 25;2(2).

6. Zou L, Ruan F, Huang M, Liang L, Huang H, Hong Z, et al. SARS-CoV-2 viral load in upper respiratory specimens of infected patients. New England Journal of Medicine. 2020 Mar 19;382(12):1177-9.

7. Liu Y, Yan LM, Wan L, Xiang TX, Le A, Liu JM, et al. Viral dynamics in mild and severe cases of COVID-19. The Lancet Infectious Diseases. 2020 Mar 19.

8. Profile of RT-PCR for SARS-CoV-2: a preliminary study from 56 COVID-19 patients | Clinical Infectious Diseases | Oxford Academic. Accessed May 8, 2020. https://academic.oup.com/cid/advancearticle/doi/10.1093/cid/ciaa460/5822175

9. Laboratory testing for 2019 novel coronavirus (2019-nCoV) in suspected human cases, https://www.cdc.gov/coronavirus/2019ncov/cases-updates/testing-in-us.html

10. ECDC Technical Report [Internet]. EU Recommendations for Testing Strategies 1 Testing of Patients with Acute Respiratory Infections or Influenza-like IIInesses in Sentinel Outpatient Clinics and among Patients Admitted to Sentinel Hospitals with Severe Acute Respiratory Infections in Order to Assess Virus Circulation in the Population. Accessed May 8, 2020. https://www.ecdc.europa.eu/sites/default/ files/documents/COVID-19-Discharge-criteria.pdf

11. LambLE, BartoloneSN, Ward E, ChancellorMB. Rapid Detection of Novel Coronavirus (COVID-19) by Reverse Transcription-Loop-Mediated Isothermal Amplification. doi:10.1101/2020.02.19.20025155

12. Li Y, Xia L. Coronavirus disease 2019 (COVID-19): role of chest CT in diagnosis and management. American Journal of Roentgenology. 2020 Jun;214(6):1280-6.

13. Chen Y, Liu Q, Guo D. Emerging coronaviruses: Genome structure, replication, and pathogenesis. J Med Virol. 2020;92(4):418-423. doi:10.1002/jmv.25681

14. Guo YR, Cao QD, Hong ZS, Tan YY, Chen SD, Jin HJ, et al. The origin, transmission and clinical therapies on coronavirus disease 2019 (COVID-19) outbreak an update on the status. Military Medical Research. 2020 Dec;7(1):1-0.

15. Coccia M. Factors determining the diffusion of COVID-19 and suggested strategy to prevent future accelerated viral infectivity similar to COVID. Science of the Total Environment. $2020 \mathrm{Apr}$ 20:138474.

16. Lau MS, Grenfell B, Nelson K, Lopman B. Characterizing superspreading events and age-specific infectivity of COVID-19 transmission in Georgia, USA. medRxiv. 2020 Jan 1.

17. Tang B, Wang X, Li Q, Bragazzi NL, Tang S, Xiao Y, et al. Estimation of the transmission risk of the 2019-nCoV and its implication for public health interventions. Journal of clinical medicine. 2020 Feb;9(2):462.

18. Wang D, Hu B, Hu C, Zhu F, Liu X, Zhang J, et al. Clinical characteristics of 138 hospitalized patients with 2019 novel coronavirus-infected pneumonia in Wuhan, China. Jama. 2020 Mar 17;323(11):1061-9. doi:10.1001/jama.2020.1585

19. Lake RJ, Kirk M. Foodborne Diseases: Prevalence of Foodborne Diseases in Australia and New Zealand. In Encyclopedia of Food Safety 2014. Elsevier Inc.

20. Udugama B, Kadhiresan P, Kozlowski HN, Malekjahani A, Osborne M, Li VY, et al. Diagnosing COVID-19: The Disease and Tools for Detection. ACS Nano. Published online April 28, 2020. doi:10.1021/ acsnano.0c02624
21. Bernheim A, Mei X, Huang $M$, Yang $Y$, Fayad ZA, Zhang $N$, et al. Chest CT findings in coronavirus disease-19 (COVID-19): relationship to duration of infection. Radiology. 2020 Feb 20:200463. doi:10.1148/ radiol. 2020200463

22. Coronavirus Update (Live): COVID-19 Virus Pandemic Worldometer https://www.worldometers.info/coronavirus/. Accessed Aug, 2020.

23. Huang C, Wang Y, Li X, Ren L, Zhao J, Hu Y, et al. Clinical features of patients infected with 2019 novel coronavirus in Wuhan, China. The lancet. 2020 Feb 15;395(10223):497-506.

24. Colavita F, Lapa D, Carletti F, Lalle E, Bordi L, Marsella P, et al. SARSCoV-2 isolation from ocular secretions of a patient with COVID-19 in Italy with prolonged viral RNA detection. Annals of Internal Medicine. 2020 Apr 17. doi:10.7326/m20-1176

25. Goyal P, Choi JJ, Pinheiro LC, Schenck EJ, Chen R, Jabri A, et al. Clinical characteristics of Covid-19 in New York city. New England Journal of Medicine. 2020 Apr 17.

26. Jones VG, Mills M, Suarez D, Hogan CA, Yeh D, Segal JB, et al. COVID-19 and Kawasaki disease: novel virus and novel case. Hospital Pediatrics. 2020 Jun 1;10(6):537-40. doi:10.1542/hpeds.2020-0123

27. Mao L, Jin $H$, Wang $M, H u ~ Y$, Chen $S, H e ~ Q$, et al. Neurologic manifestations of hospitalized patients with coronavirus disease 2019 in Wuhan, China. JAMA neurology. 2020 Jun 1;77(6):683-90. doi:10.1 101/2020.02.22.20026500

28. Klok FA, Kruip MJ, Van der Meer NJ, Arbous MS, Gommers DA Kant KM, et al. Incidence of thrombotic complications in critically ill ICU patients with COVID-19. Thrombosis research. $2020 \mathrm{Apr} 10$. doi:10.1016/j.thromres.2020.04.013

29. Zhou F, Yu T, Du R, Fan G, Liu Y, Liu Z, et al. Clinical course and risk factors for mortality of adult inpatients with COVID-19 in Wuhan, China: a retrospective cohort study. The lancet. 2020 Mar 11. doi:10.1016/S0140-6736(20)30566-3

30. Laboratory testing for 2019 novel coronavirus (2019-nCoV) in suspected human cases. Accessed May 8, 2020. https://www.who.int/ publications-detail/laboratory-testing-for-2019-novel-coronavirus-insuspected-human-cases-20200117

31. European Centre for Disease Prevention and Control (ECDC). Novel coronavirus disease 2019 (COVID-19) pandemic: increased transmission in the EU/EEA and the UK - sixth update [Internet]. Stockholm, Sweden; 2020. Available from:https://www.ecdc.europa. eu/sites/default/files/documents/RRA-sixth-updateOutbreak-ofnovel-coronavirus-disease-2019-COVID -19.pdf

32. Udugama B, Kadhiresan P, Kozlowski HN, Malekjahani A, Osborne M, Li VY, et al. Diagnosing COVID-19: the disease and tools for detection. ACS nano. 2020 Mar 30;14(4):3822-35. doi:10.1021/acsnano.0c02624

33. Protocol: Real-Time RT-PCR Assays for the Detection of SARS-CoV-2.

34. NPHL | Pages. Accessed May 8, 2020. https://www.nphl.gov.np/ page/ncov-related-lab-information

35. Wong JEL, Leo YS, Tan CC. COVID-19 in Singapore - Current Experience: Critical Global Issues That Require Attention and Action. JAMA Journal of the American Medical Association. 2020;323(13):12431244. doi:10.1001/jama.2020.2467

36. Laboratory testing for 2019 novel coronavirus (2019-nCoV) in suspected human cases. Accessed May 8, 2020. https://www.who.int/ publications-detail/laboratory-testing-for-2019-novel-coronavirus-insuspected-human-cases-20200117

37. Winter AK, Hegde ST. The important role of serology for COVID-19 control. The Lancet Infectious Diseases. 2020 Jul 1;20(7):758-9.

38. LvH, Wu NC, Tsang OT, Yuan M, Perera RA, Leung WS, et al. Cross-reactive antibody response between SARS-CoV-2 and SARS-CoV infections. Cell Reports. 2020 May 18:107725. doi:10.1101/2020.03.15.993097

39. Guo L, Ren L, Yang S, Xiao M, Chang D, Yang F, et al. Profiling early humoral response to diagnose novel coronavirus disease (COVID-19). Clinical Infectious Diseases. 2020 Mar 21. doi:10.1093/cid/ciaa310 